\title{
UNTREATED SINUSITIS - THE HIDDEN ENEMY OF THE BRAIN
}

\author{
Iulia SIMA ${ }^{1}$, Eliza M. POPA ${ }^{1 凶}$, Lavinia RAICU ${ }^{1}$, Rosana MANEA ${ }^{1,2}$ \\ ${ }^{1}$ Department of Radiology and Medical Imaging, Clinical and Emergency Hospital, Brasov, Romania \\ ${ }^{2}$ Faculty of Medicine, "Transilvania” University of Brasov, Romania
}

Received 30 July 2021, Accepted 26 Aug 2021

https://doi.org/10.31688/ABMU.2021.56.3.13

\begin{abstract}
Introduction. Sinusitis is caused by allergens, viruses, fungi or bacteria. The main signs of the disease are those of a common cold. Untreated sinusitis can lead to severe orbital or intracranial complications, such as brain abscess.
\end{abstract}

Case presentation. We present the case of a 52-year-old man who presented to the emergency department with aphasic speech disorders and headache persisting for two days. After computed tomography (CT) evaluation, the suspicion was raised of a brain abscess and subdural empyema, with the starting point in the paranasal sinus infection. The treatment included neurosurgery and broad-spectrum antibiotics continuously for 4 weeks. The aim of this case study is to underline the importance of properly administered treatment in chronic sinusitis and the severity of the complications that may occur.

Conclusions. Untreated sinusitis can lead to life-threatening complications, such as brain abscess and subdural empyema, even though the symptoms are often ignored. For the complete diagnosis and further treatment, the use of $\mathrm{CT}$ and magnetic resonance imaging (MRI) is necessary.

Keywords: paranasal sinuses, sinusitis, intracranial abscess, empyema.

\section{Résumé}

La sinusite non traitée - l'ennemi caché du cerveaux

Introduction. La sinusite est causée par des allergènes, des virus ou des bactéries. Les principaux signes sont ceux d'un rhume, mais une sinusite non traitée peut entraîner de graves complications orbitaires ou intracrâniennes, telles qu'un abcès cérébral.

Présentation du cas. Nous présentons le cas d'un homme de 52 ans admis aux urgences pour troubles aphasiques de la parole. Le patient a accusé des maux de tête qui ont persisté pendant deux jours. Après une évaluation par tomodensitométrie (CT), on a évoqué la suspicion d'un abcès cérébral et d'un empyème sous-dural avec comme point de départ l'infection des sinus paranasaux. Le traitement comprenait une intervention neurochirurgicale et des antibiotiques à large spectre en continu pendant 4 semaines. Le but de cette étude de cas est de souligner l'importance d'un traitement correctement administré dans la sinusite chronique et la gravité des complications qui peuvent survenir.

Conclusion. Une sinusite non traitée peut entraîner des complications potentiellement mortelles telles qu'un abcès cérébral et un empyème sous-dural, même si les symptômes sont souvent ignorés. Pour le diagnostic complet et le traitement ultérieur était nécessaire 


\section{List of abbreviations:}

CT - computed tomography

MRI - magnetic resonance imaging

DWI - diffusion weighted imaging

ADC - apparent diffusion coefficient

FLAIR - fluid attenuated inversion recovery

\section{INTRODUCTION}

Sinusitis is a frequent community infection with a favorable evolution in the vast majority of cases. The paranasal sinuses become inflamed, with mucosal thickening, and sometimes intracranial or systemic complications may occur. Intracranial abscess is a life-threatening empyema-associated infection that may arise from contiguous structures, such as paranasal sinuses, requiring immediate diagnosis and therapy ${ }^{1}$. Fungal sinus infections have some particularities, such as the presence of intrasinus calcification at computed tomography (CT) scan ${ }^{2}$.

The purpose of this case study is to highlight the contribution of superior imaging modalities, CT and magnetic resonance imaging (MRI), in the diagnosis and post-treatment monitoring of sinusitis complications.

\section{Case presentation}

A 52-year-old man, with no medical history or background therapy, was admitted to the hospital with aphasic speech disorders and headache, persisting for two days, for which he had self-administered a nonsteroidal anti-inflammatory drug.

The clinical examination revealed an overweight patient, with normally conformed chest, accentuated l'utilisation de l'imagerie CT et (imagerie par résonance magnétique) IRM.

Mots-clés: sinus paranasaux, sinusite, abcès intracrânien, empyème.

vesicular murmur, blood pressure 129/74 mmHg, rhythmic heart sounds and normal body temperature. The neurological examination on admission showed a conscious patient, with severe mixed aphasia mainly expressive, without motor deficits, without segmental ataxia, with normal deep tendon reflexes, who did not cooperate for the examination of superficial sensitivity.

The blood tests at admission revealed leukocytosis with neutrophilia, severe inflammatory syndrome, increased ferritin and moderate hyponatremia.

A contrast-enhanced CT scan was performed (Figure 1), that raised the suspicion of a brain abscess, with the starting point in a left-sided paranasal sinusitis.

After two days of hospitalization, the patient's condition worsened, with fever $\left(38^{\circ} \mathrm{C}\right)$, oxygen level $94 \%$ in arterial blood gases, normal blood pressure. The neurological reevaluation revealed global aphasia and right hemiplegia. The patient had partial motor seizures on the right side of the body, and antiepileptic medication was administered.

The MRI examination of the brain revealed a left frontal lobe cerebral abscess, with aspect of meningoencephalitis in the left cerebral hemisphere, left-sided subdural fronto-parieto-occipital empyema, and acute left-sided paranasal sinusitis (Figure 2).

Four days after admission to the hospital, the patient was examined by an otorhinolaryngology

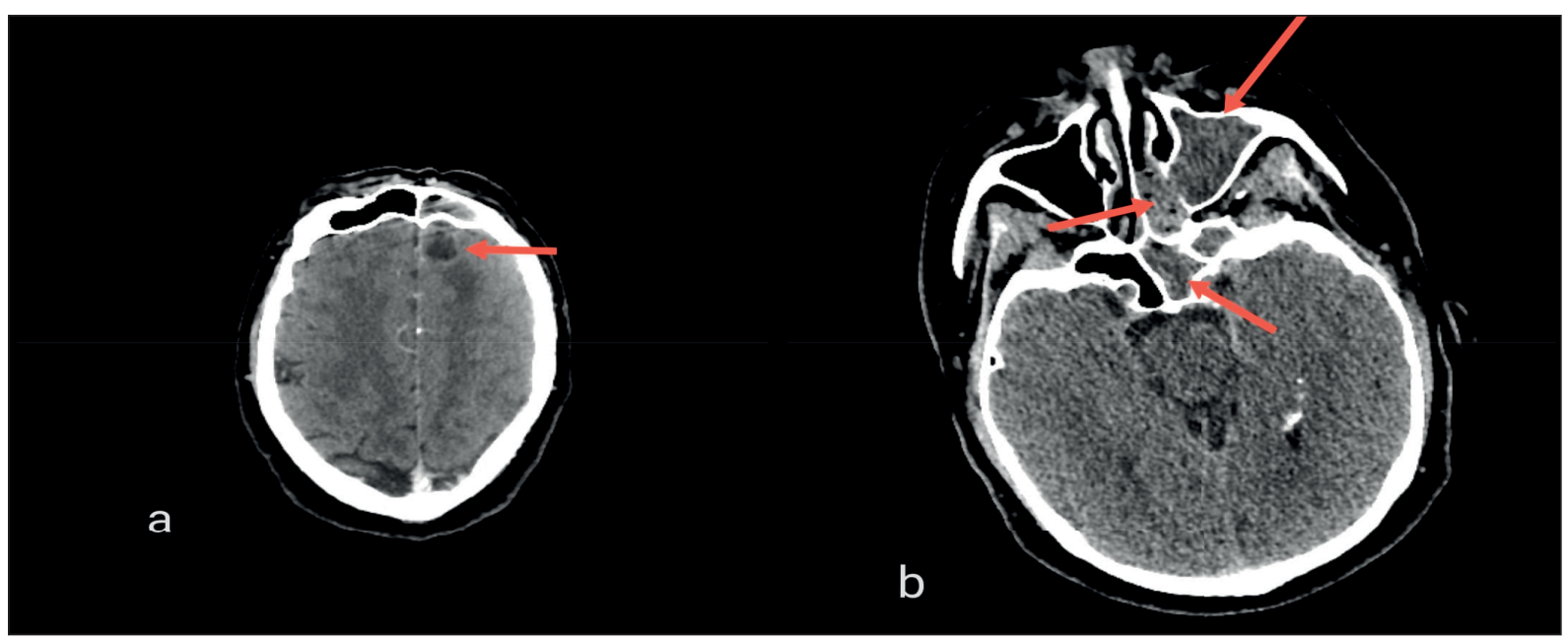

Figure 1. Contrast-enhanced CT scan highlights: a. $1.6 \mathrm{~cm}$ hypodense area with peripheral enhancement, perilesional edema and acute frontal sinusitis; b. acute left maxillary, sphenoidal sinusitis, also infection of the left ethmoidal air cells. 
specialist, who performed left sphenoidectomy, left maxillary sinus antrostomy, left frontal antrostomy, and excision of the polypoid mucosa.

A CT scan was performed four days after, and revealed no major changes compared to the MRI examination (Figure 3).
Another control contrast-enhanced CT scan was performed six days after the patient was admitted to the hospital, that revealed the appearance of new intracerebral lesions (Figure 4).

Two days after the last CT scan, a contrast-enhanced MRI examination was performed, that

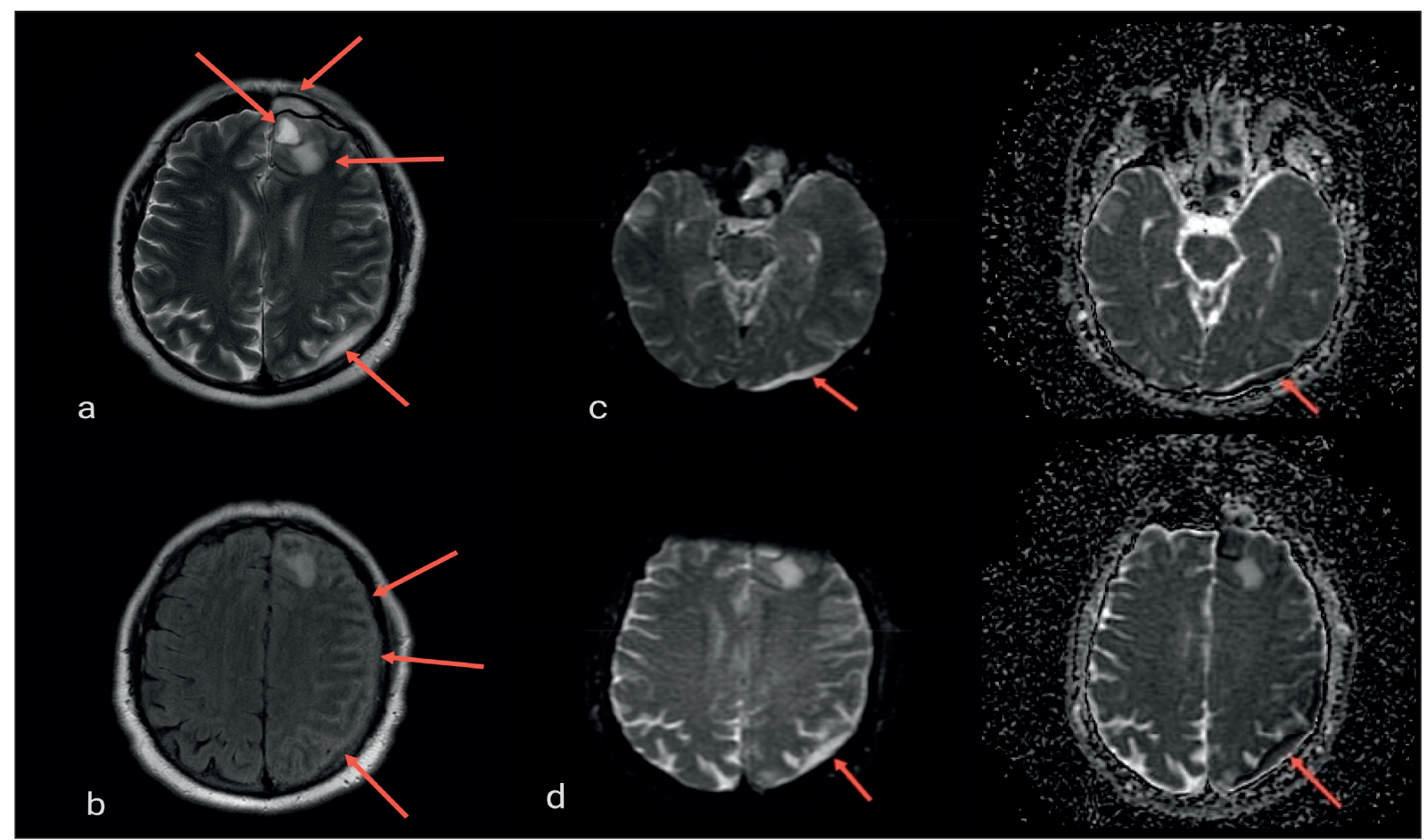

Figure 2. MRI highlights: a. T2 sequence shows a hyperintense well-circumscribed 20/15 mm lesion in the left frontal lobe with thin hypointense wall and moderate hyperintense perilesional signal suggestive of edema, also left frontalis acute sinusitis; b. T2 fluid-attenuated inversion recovery (FLAIR) indicates a discreet hyperintense signal of the meninges from the left hemisphere; c-d. Diffusion-weighted imaging (DWI)/ apparent diffusion coefficient (ADC) maps: restricted diffusion subdural areas suggestive for empyema.

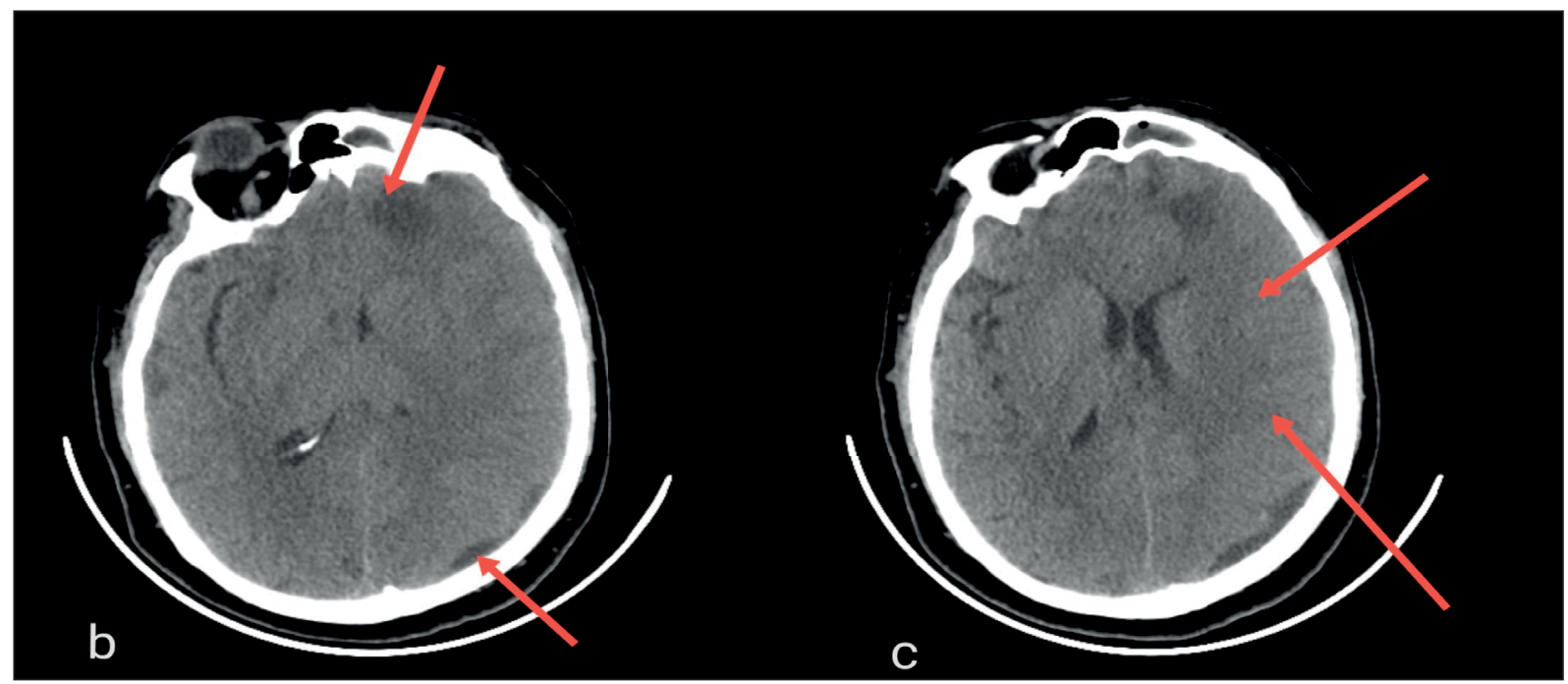

Figure 3. CT scan highlights: a-b. $1.3 \mathrm{~cm}$ left frontal hypodense lesion, relatively well-circumscribed, with moderate hypodense perilesional area suggestive of edema and left occipital and parietal subdural collections; c. diffuse cerebral edema in the left cerebral hemisphere that causes compression of adjacent gyri. 


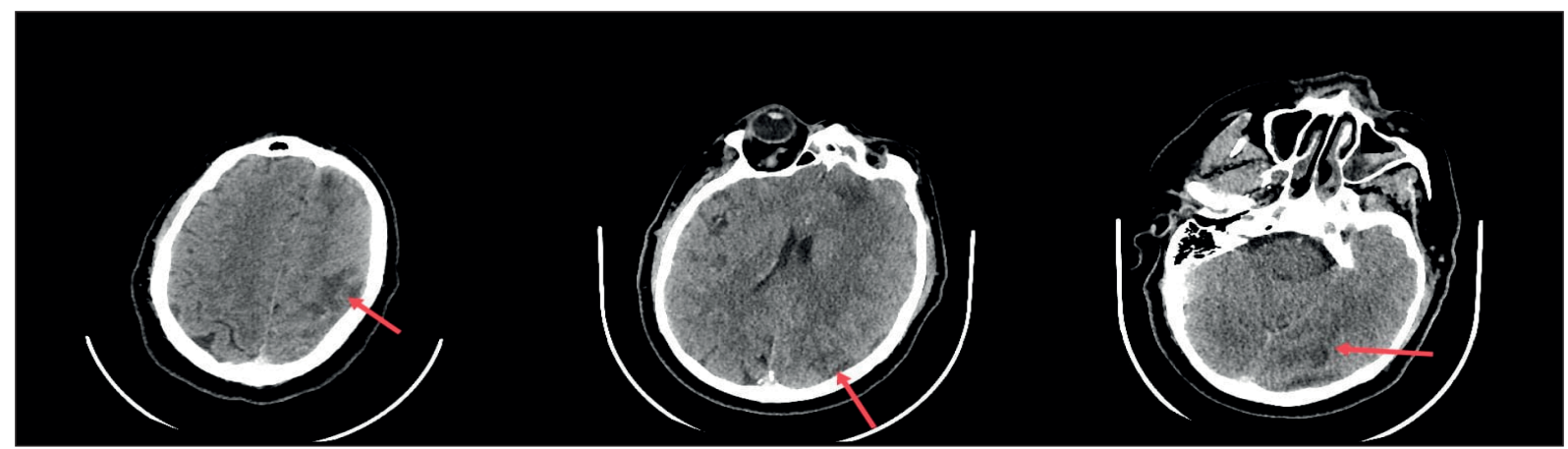

Figure 4. Contrast-enhanced CT scan highlights new hypodense lesions in the left cerebral hemisphere frontal, parietal and occipital lobes, with discreet enhancement. The previous lesions are unchanged.

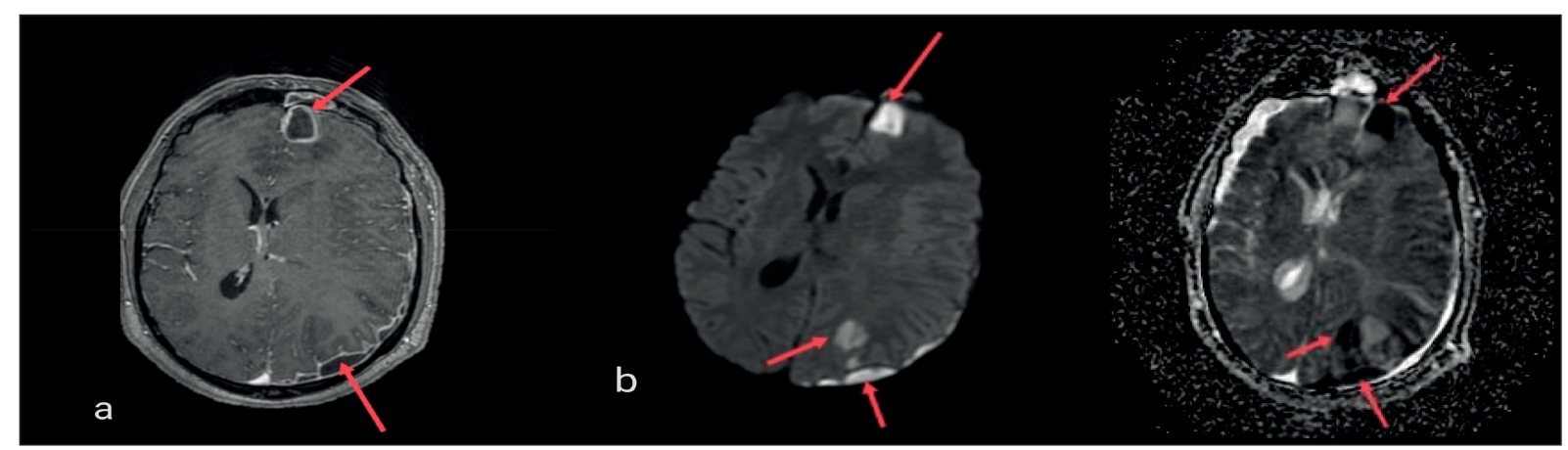

Figure 5. a. T1- weighted contrast-enhanced MRI highlights a hypointense left frontal lesion with peripheral enhancement (abscess), that increased in size from 20/15 $\mathrm{mm}$ to $22 / 19 \mathrm{~mm}$, and hypointense left parietal subdural lesions (empyema); b. DWI/ADC: restricted diffusion of the lesions.

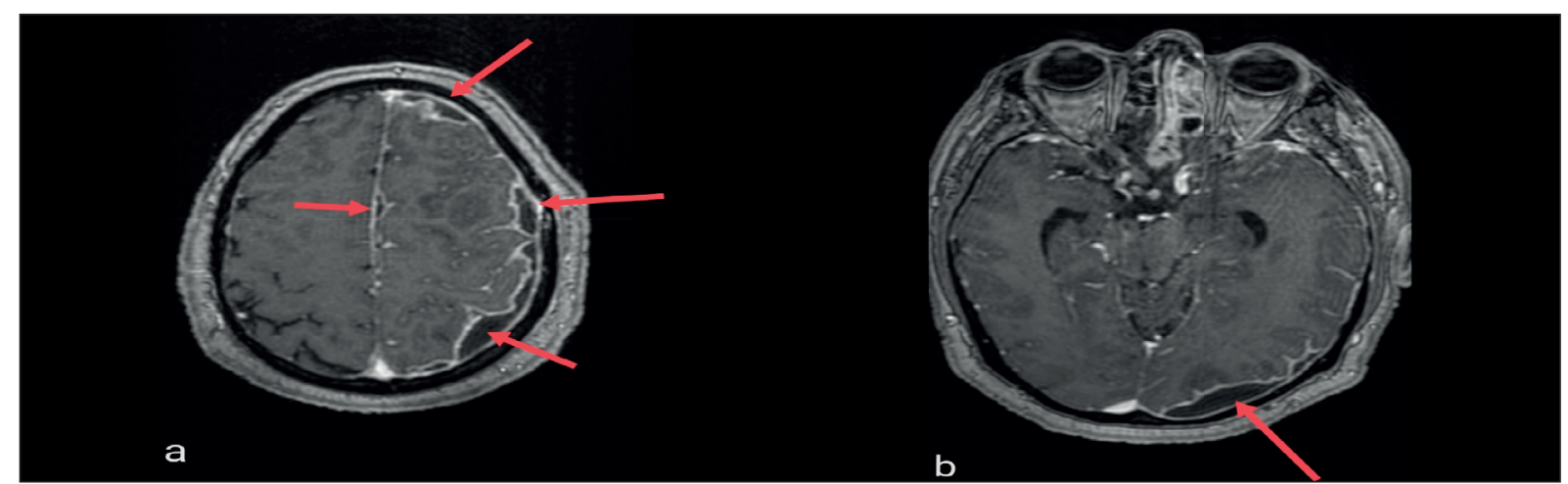

Figure 6. T1- weighted contrast-enhanced MRI: a. the appearance of new lesions in the interhemispheric fissure, approximately $5 \mathrm{~mm}$ in size; a-b. increased size of the left subdural empyema compared to the previous examination; all the lesions have peripheral enhancement.

revealed a worsened aspect of the brain, with increased size of the abscess, subdural empyema and the appearance of new lesions (Figures 5, 6, 7).

Because of the worsened evolution of intracerebral injuries, eight days after the patient was first admitted to the hospital, a neurosurgery was performed for empyema drainage. The other three CT scans were performed the next day, five days and two weeks after surgery (Figure 8).

About a month after the onset of symptoms, the patient had a clinically favorable evolution, with hemodynamic and respiratory stability, was conscious, cooperative, with no signs of intracranial hypertension, without motor deficit, afebrile.

\section{Discussion}

Sinusitis is a common health problem with high prevalence in Europe. In a study of 57,128 patients from 12 countries, by Hastan et al., about one in ten patients had chronic sinusitis ${ }^{3}$. 


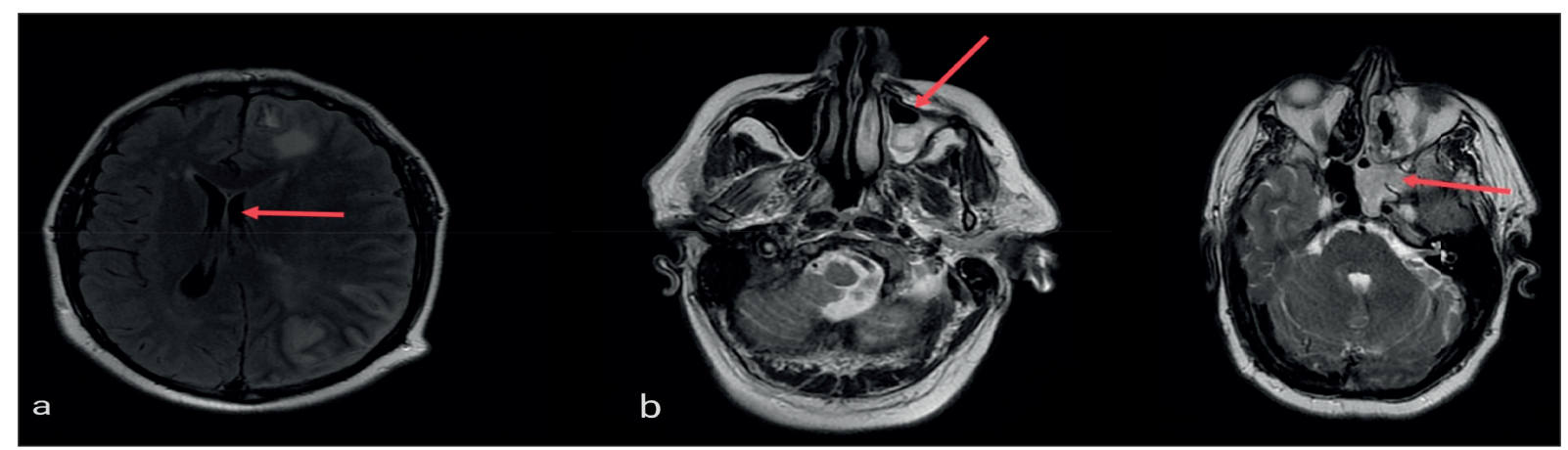

Figure 7. a. T2 FLAIR highlights a hyperintense signal of the abscess, perilesional edema and subdural empyema, with mass effect that causes a midline shift to the right by approximately $8 \mathrm{~mm}$;

b. Important left maxillary and sphenoid sinuses changes.

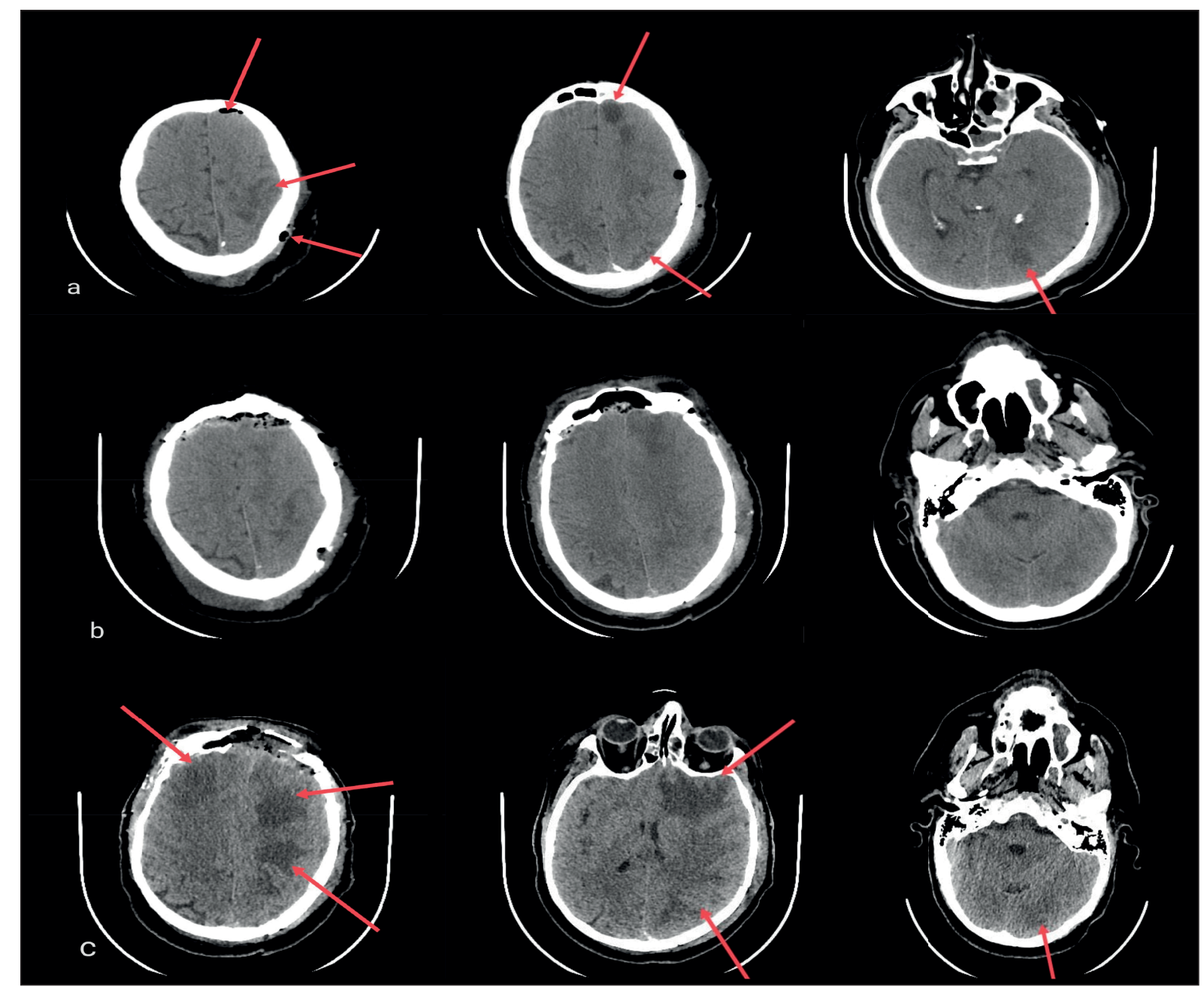

Figure 8. After surgery, CT scan highlights: a. After the first day - minimum pneumocephalus postoperatively, hypodense cortico-subcortical left areas frontal, parietal and occipital; b. After five days - the persistence of pneumocephalus and of hypodense cortico-subcortical left areas, with no significant changes; c. After two weeks - increased hypodense areas with the appearance of a new one in the right frontal lobe.

The early diagnosis and right treatment of complicated sinusitis have great importance, because this infection can threaten survival $1^{4}$.

We presented the case of a patient with paranasal sinus infection leading to intracerebral lesions, cerebral abscess in the left frontal lobe, meningoencephalitis and subdural empyema.

According to the literature, the exact mechanism of the intracranial spread of infection is not clear yet. Germiller et al., in their study, revealed that 
in most of the cases it may occur by the dissemination of infected thrombi through a net of veins which have connections with the veins of the skull and dura mater ${ }^{5}$. The lack of valves of these veins is one of the factors that increase the possibility of thrombus formation. Also, the spread is possible if there are bone tissue losses because of osteomyelitis or if there are congenital or acquired bone defects within the sinus walls. Their study included 25 children hospitalized with sinusitis between 1999 and 2004, and the most frequent complications were focal collections, but also meningitis, encephalitis, and dural sinus thrombophlebitis ${ }^{5}$.

Gallagher and his collaborators, in a retrospective review of the literature published between 1992 and 1997, identified 176 cases of patients with intracranial suppuration: 15 patients had suppurative intracranial complications of sinusitis, such as epidural abscess (23\%), subdural empyema (18\%), meningitis (18\%), cerebral abscess (14\%), superior sagittal sinus thrombosis (9\%), cavernous sinus thrombosis (9\%), and osteomyelitis $(9 \%)^{6}$.

In a study conducted by Clayman and his collaborators, between 1975-1988, 24 out of 649 patients developed intracranial complications of paranasal sinusitis. The most frequent intracerebral lesions were frontal lobe abscess (46\%), meningitis (29\%), and subdural empyema $(8 \%)^{7}$.

Also, Younis et al. have found that among the 82 patients who had been admitted for the treatment of sinusitis' complications, 43 had orbital complications and 39 had intracranial complications. In their study, meningitis was the most frequent intracranial complication, and other findings included epidural abscess, subdural abscess, intracerebral abscess, and superior sagittal sinus thrombosis ${ }^{8}$.

In a study of patients with sinusitis complicated by epidural abscess, Hong et al. showed that patients' symptoms were weakness, frontal headache, sinus pain and nasal congestion, while in our patient the symptoms were aphasic speech disorders and headache, that persisted for two days ${ }^{9}$. The symptoms of complicated sinusitis can be confusing for the clinician, but the imaging data obtained by CT and MRI can be useful for the correct diagnosis and selection of the best therapeutic protocol ${ }^{10,11}$.

In a study conducted between 1990 and 1999, Albu et al. discovered that the most frequent symptoms of chronic sinusitis were headache and fever, and that the use of CT and MRI imaging was necessary for the complete diagnosis ${ }^{12}$.

The intracranial complications of sinusitis require a combination of systemic antibiotherapy and surgical drainage, because patients' condition may progressively deteriorate.

\section{Conclusions}

We presented the case of a 52-year-old man who was admitted for aphasic speech disorders and headache, persisting for two days. The images obtained from CT scan and MRI were very useful in selecting the best surgical technique, because drainage of the abscess was necessary, and also for subsequent monitoring. The evolution of the patient was favorable about a month after the onset of symptoms, with no signs of intracranial hypertension, motor deficit or fever.

The prognosis of the brain abscess is poor, with longer hospitalization and higher mortality, therefore a rapid diagnosis and treatment are required.

\section{Author Contributions:}

I.S., L.R., E.M.P. and R.M. were responsible for drafting and designing the manuscript. I.S. was responsible for the diagnostic procedures, clinical diagnosis and treatment decisions. L.R. and E.M.P. wrote the manuscript. R.M., E.M.P and L.R. revised and approved the manuscript. All authors have read and agreed to the published version of the manuscript.

\section{Compliance with Ethics Requirements:}

"The authors declare there is no conflict of interest regarding this article"

"The authors declare that all the procedures and experiments of this study respect the ethical standards in the Helsinki Declaration of 1975, as revised in 2008(5), as well as the national law."

"The patient signed a written informed consent to publish his case"

"No funding for this study"

\section{Acknowledgements:}

None

\section{References}

1. Gwaltney JM Jr. Acute community: acquired sinusitis. Clinical Infectious Diseases. 1996; 23(6):1209-23.

2. Sechel G, Repanovici A, Manea R, Burtea V. The imaging evaluation of typical and atypical calcifications in different anatomical regions study in Brasov, Romania. The Medical-Surgical Journal 2020; 124(2): 290-297.

3. Hastan D, Fokkens WJ, Bachert C, et al. Chronic rhinosinusitis in Europe - an underestimated disease. A GA²LEN study. Allergy. 2011; 66(9):1216-23.

4. Szyfter W, Kruk-Zagajewska A, Bartochowska A, Borucki L. Intracranial complications from sinusitis. Otolaryngologia Polska. 2015; 69(3):6-14.

5. Germiller JA, Monin DL, Sparano AM, et al. Intracranial complications of sinusitis in children and adolescents and 
their outcomes. Archives of Otolaryngology - Head $\mathcal{E}$ Neck Surgery. 2006; 132 (9):969-976.

6. Gallagher RM, Gross CW, Phillips CD. Suppurative intracranial complications of sinusitis. Laryngoscope. 1998; 108 (11 Pt 1):1635-42.

7. Clayman GL, Adams GL, Paugh DR, Koopmann CF Jr. Intracranial complications of paranasal sinusitis: a combined institutional review. Laryngoscope. 1991; 101(3):234-9.

8. Younis RT, Lazar RH, Anand VK. Intracranial complications of sinusitis: a 15-year review of 39 cases. Ear, Nose $\mathcal{E}$ Throat Journal. 2002; 81(9):636-8, 640-2, 644.
9. Hong P, Pereyra CA, Guo U, Breslin A, Melville L. Evaluating complications of chronic sinusitis. Case Reports in Emergency Medicine. 2017; 2017:8743828.

10. Kolsi N, Zrig A, Chouchène H, Bouatay R, Harrathi K, Koubaa J. Imaging of complicated frontal sinusitis. The Pan African Medical Journal. 2017; 26:209.

11. Dankbaar JW, Bemmel AJM, Pameijer FA. Imaging findings of the orbital and intracranial complications of acute bacterial rhinosinusitis. Insights Imaging. 2015; 6(5):509-518.

12. Albu S, Tomescu E, Bassam S, Merca Z. Intracranial complications of sinusitis. Acta Oto-rhino-laryngologica Belgica 2001; 55(4):265-72 